\title{
Human sirtuins: structures and flexibility
}

\author{
Lionel Sacconnay ${ }^{\mathrm{a}^{*}}$, Pierre-Alain Carrupt ${ }^{\mathrm{a}}$, Alessandra Nurisso ${ }^{*^{\mathrm{a}, \mathrm{b}}}$

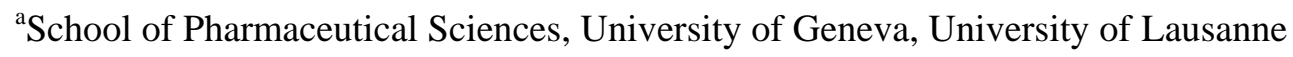 \\ Rue Michel Servet 1, CH-1211, Geneva 4, Switzerland \\ bépartement de Biochimie, Université de Montréal, H3C 3J7 Montréal, Québec, Canada
}

\begin{abstract}
In recent years, sirtuins (SIRTs), members of histone deacetylases (HDACs) class III, have been found to modulate cellular processes related to the development of human aging-related pathologies (i.e. cancer, neurodegeneration, metabolic disorders). Several crystallographic structures and computational studies have shed light into their catalytic mechanism of action, identifying also the structural elements for the design of selective drug candidates. In this review, we first aim at summarizing the structural features characterizing human SIRTs. We then describe the observed mass and one-off movements related to conformational changes upon SIRT-mediated recognition events. Such information will be useful not only for rationalizing the design of new SIRT modulators, but also for improving the comprehension of SIRT-related biological roles.
\end{abstract}

\section{Key-words}

Sirtuins, conformational changes, protein-protein interactions, modulators, structure-based drug design

\section{Abbreviations}

ECS, extended C-site; HDACs, histone deacetylases; SIRTs, sirtuins; 3D, three-dimensional. 


\section{Introduction}

In 1987, Rine et al., identified four proteins responsible for the silencing of the Hidden MAT loci of Saccharomyces cerevisiae, implicated in the mating process of the yeast (Rine and Herskowitz, 1987). These four proteins, called silent information regulatory (Sir) proteins, have been found to bind to the nucleosome through interactions with histone proteins $\mathrm{H} 3$ and $\mathrm{H} 4$, and to repress gene expression ( Johnson et al., 1990; Murphy et al., 2003; Cubizolles et al., 2006; Ehrentraut et al., 2011; Oppikofer et al., 2013). Sir proteins have aroused great hope when it was found that they may participate in extending the yeast life span (Lin et al., 2004). As Sir homologous proteins have been found in many organisms including mammals, this opened a new hope for the development of novel therapeutic treatments. The human genome encodes for seven Sir-like proteins, commonly called sirtuins (SIRTs, Fig. 1) (Frye, 1999; Frye, 2000). Phylogenetically, they belong to the class III histone deacetylase (HDAC) family (Gray and Ekström, 2001). In contrast to class I, II and IV HDACs, which are all zincdependent enzymes, SIRTs have been found to be nicotinamide adenine dinucleotide $\left(\mathrm{NAD}^{+}\right)$ dependent enzymes able to generate 1-O-acetyl-ADP-ribose as a by-product (Imai et al., 2000; Tanner et al., 2000). As members of the HDAC family, SIRTs possess deacetylase activity. However, other catalytic activities have been reported for certain isoforms. For example, SIRT4 has been found to have low deacetylase activity, and a main ADP ribosyltransferase one (Ahuja et al., 2007). SIRT5 has been found to prefer succinyl, malonyl and glutaryl lysine substrate with low deacetylase activity reported (Du et al., 2011; Peng et al., 2011). And regarding SIRT2, which main activity is the deacetylation of lysine substrate, it has been reported that like SIRT6 to also possess demyristoylation activity (Teng et al., 2015).The SIRT cellular localization is isoform-dependent, and can be subjected to compartment shuttling during particular cell cycle phases, also in response to diverse cellular stress Michishita et al., 2005; Vaquero and Reinberg, 2009; Bosch-Presegue and Vaquero, 2014). Whereas SIRT1, SIRT6, and SIRT7 are the isoforms mainly found in the nucleus, where they can exert their activity by regulating DNA stability, gene expression, chromatin structure maintenance and/or cellcycle progression (Michishita et al., 2005), SIRT2 has been found to co-localize and deacetylate $\alpha$ tubulin in the cytoplasm. This suggests that SIRT2 plays a role in maintaining cellular architecture and division. Interestingly, SIRT2 was found to be shuttled into the nucleus of the cell during mitosis 
where it promotes G2/M transition through the deacetylation of histone H4K16 (North et al., 2003). SIRT3, SIRT4, and SIRT5 are mitochondrial SIRTs that mainly interact with non-histone proteins on which they exert their catalytic activity ( Onyango et al., 2002; Michishita et al., 2005). Diseases associated with SIRT-related cellular mechanisms (e.g. cancer, neurodegeneration, and metabolic disorders) have received considerable attention in research in recent decades due to their impact on the healthcare systems (Mariotto et al., 2011). For this reason, SIRTs are now considered promising therapeutic targets. For reviews on SIRT-related cellular mechanisms, and on the recent advances in the discovery of chemical modulators of SIRTs, please refer to ( Villalba et al., 2012; Anderson et al., 2014; Carafa et al., 2016; Mellini et al., 2015).

In this manuscript, a summary of the structural features characterizing human SIRT proteins is reported. We then focus our attention on the massive movements characterizing SIRTs, induced by the binding of biological partners. Residues responsible of one-off movements in SIRT binding sites, exerting a fundamental role in molecular recognition, are also identified. We conclude by highlighting how this structural data can be useful for the design of new selective and potent SIRT modulators, and which are the missing structural data that are required to fully understand SIRT-related biological roles.

\section{Common structural features of human SIRT proteins}

Structurally, human SIRT proteins share a common catalytic core of around 250 amino-acids, with Nand C-terminal regions of variable length (Fig. 1). Those regions seem to be able to acquire different conformational states, also upon post-translational modifications, that may explain their ability to bind multiple partners, and to exert multiple roles in cells ( North and Verdin, 2007; Pandithage et al., 2008; Grob et al., 2009; Costantini et al., 2013) (Fig. S1). The importance of the terminal regions was also highlighted by the work from Kang et al., in which they demonstrated the essential role of 25 residues (from Gln641 to Val665) localised at the C-terminal region of SIRT1 for catalytic activity modulation. This peptide sequence is in fact able to interact with the core domain, inducing conformational changes that increase the affinity of SIRT1 for its substrate (Kang et al., 2011). 
Structural information regarding the behaviour of those regions is lacking for the other SIRT isoforms so far.

SIRT2 was the first human isoform to be crystallised in 2001 by Finnin et al., and provided a useful insight into the organisation of the SIRT catalytic core (Fig. 2A) (Finnin et al., 2001). The SIRT catalytic core is organised as follow: i) a large domain characterized by an inverted Rossmann fold, typical of an NAD(H)/NADP(H) binding enzyme (Bellamacina, 1996; Finnin et al., 2001), which consists of six $\beta$-strands, organised in a parallel $\beta$-sheet, and of six $\alpha$-helices packing against the $\beta$ sheet; ii) a small domain composed of two modules, one with four $\alpha$-helices, called helical module, and the other one with a structural zinc ion, tetra-coordinated by four Cys residues, called zinc module (Finnin et al., 2001). A binding site accommodating both acetylated substrates and NAD ${ }^{+}$is found at the interface of the two domains, linked to each other by two flexible loops (L1 and L2). L3 also takes part in the formation of the binding site, and participates in stabilizing the binding of acetylated substrates (Fig. 2A, Fig. 2B).This binding site is composed by a $\mathrm{NAD}^{+}$binding pocket, and by a lysine channel (Fig. 2A). The NAD ${ }^{+}$binding pocket is characterised by three sub-pockets. The ADP-ribose moiety binds to the sub-pocket A. Nicotinamide-ribose accommodates in the B sub-pocket while, during catalysis, it occupies the $\mathrm{C}$ sub-pocket, characterised by the TQNXD sequence (Fig. S2), allowing the transfer of the acetyl group from the Lys residue of a protein substrate to the ribose of $\mathrm{NAD}^{+}$. The lysine channel, able to accommodate acetylated substrates, consists of a narrow channel adjacent to the NAD ${ }^{+}$binding pocket (B sub-pocket, Fig. 2A).

To date, 62 crystals of human SIRTs catalytic core have been reported in the Protein Data Bank (PDB) (http://www.rcsb.org/, accessed: June $17^{\text {th }}$ 2016), providing insight into the different stages of SIRT catalytic cycles. As yet, no structures have been elucidated for SIRT4 and SIRT7 isoforms. Details are reported in Table 1. Unfortunately, until now, a structure-based strategy for the discovery of SIRT isoform-selective modulators has been difficult to set up due to the high structural similarity among SIRT catalytic cores.

\section{Human SIRTs are flexible proteins undergoing massive and punctual conformational}

\section{changes}




\subsection{Substrate binding induces a massive rearrangement of the SIRT catalytic core domain}

It has been observed that SIRT proteins are able to adopt different conformational states. Moniot et al. first described how SIRT2 can switch from an apo conformation (open) to a productive conformation (closed) upon substrate and $\mathrm{NAD}^{+}$binding (Moniot et al., 2013). Substrate binding results in a $25^{\circ}$ rotation of the small domain compared to the Rossmann fold, leading to the rearrangement of the L1L3 loops (Fig. 2B):

- $\quad$ L1 is reoriented in order to interact with ADP-ribose and therefore to enclose the C subpocket of the $\mathrm{NAD}^{+}$binding site. This is accompanied by a $45^{\circ}$ reorientation, compared to the apo conformation, of the $\alpha$-helix of L1, along its unwinding. Such conformational change has been previously reported to occur upon $\mathrm{NAD}^{+}$binding by Sakkiah et al., using molecular dynamics simulation of docking complexes obtained from the apo SIRT2 isoform (Sakkiah et al., 2012; Sakkiah,S. et al., 2013a; Sakkiah,S. et al., 2013b).

- $\quad$ L2 moves close to the $\mathrm{NAD}^{+}$binding loop L1, creating a channel able to interact with the acetylated lysine substrates in the pocket.

- $\quad$ L3, found in the large domain, undergoes conformational changes interacting with ADP-ribose as a result of the side chain reorientations of two conserved residues (Val266 and Ser263, Fig. 5). This conformational change also helps in stabilizing the acetylated substrates into the lysine channel.

Similar behaviour upon substrate and/or NAD ${ }^{+}$binding has been described in the literature for SIRT1, SIRT3, and SIRT5 isoforms (Jin et al., 2009; Zhou et al., 2012; Zhao et al., 2013).

Currently, no structural information is available for SIRT4, and no assumptions concerning the flexibility of its catalytic pocket can be done since this enzyme exhibits better ADP-ribosyl transferase rather than deacetylase activity (Ahuja et al., 2007). L1-L3 sequences are highlighted in Fig. S2.

\subsection{SIRT6: elements of structural specificity}

Pan et al. reported the lack of the helical module characterizing the small domain of SIRT6, which was present in the other SIRT isoforms (Fig. 2C). This particular feature was proposed to explain the observed rigidity of L1 in SIRT6, even in the absence of a NAD ${ }^{+}$molecule (Pan et al., 2011). Indeed, 
the zinc-binding domain of SIRT6, being unable to interact with the helical module, leads to a more flaring small domain that is positioned in an open conformation through direct interaction with the large domain, tilting at an angle of $45^{\circ}$ compared to the Rossmann fold. Pan et al. also reported the presence of a highly flexible loop, connecting zinc-binding Cys residues (Fig. 2C), but did not provide any information about its effect on SIRT6 activity. The zinc-binding domain is thought to modulate substrate-specific binding (Zhao et al., 2004). It can be hypothesised that such a loop may play a role in this specific recognition. Even though a crystallographic structure has not been resolved yet, a similar behaviour for SIRT7 was proposed, considering the lack of the helix bundle in the small domain (Pan et al., 2011).

With regard to L2, Jiang et al. observed in SIRT6 the same movements as in the other isoforms, upon long-chain fatty acyl lysine substrate binding (Jiang et al., 2013). However, Pan et al. described a difference in backbone orientation of the Trp186 residue compared to the Phe residue conserved in other SIRT isoforms (Fig S2). This difference was proposed as an explanation for the decreased deacetylase activity observed in SIRT6: the substrate cannot interact efficiently with the protein due to the orientation of Trp186.

\subsection{Loops modulate isoform-specific protein-protein interactions}

As previously mentioned, the organisation of the SIRT catalytic core is relatively well conserved among all members of the SIRT family (Fig. 1A). However, there are zones, out of the catalytic pocket, that may be involved in the specific recognition of biological partners. Moniot et al. reported the presence in SIRT2 of a distinctive flexible loop in the Rossmann fold, composed by 15 residues (from Ser293 to Met307) (Kang et al., 2011; Moniot et al., 2013) (Fig. 3A).

In the apo conformation of SIRT2, the loop appears to be very well organized (yellow loop, Fig. 3A) forming an $\alpha$-helix structure. In the productive conformation, upon substrate and $\mathrm{NAD}^{+}$binding, this loop appeared to be completely disorganised (dark green loop, Fig. 3A), with the loss of the $\alpha$-helix structure. The $\beta$-factor analysis for this loop indicates, surprisingly, a great stability in both conformational states. Moniot et al. therefore proposed a protein-protein interaction mediating role for this loop, based on the fact that it is known to be responsible for the artificial crystal dimerization of 
SIRT2 apo conformation. Moreover, in the crystallographic productive conformation, this loop was found to mediate the interaction with other chains present in the asymmetric unit through a Leu residue (Leu297) that may mimic the acetyl chain of substrates (Moniot et al., 2013).

In SIRT5, Schuetz et al. described a loop (from Ala183 to Leu204) inserted in the zinc-binding domain overlaying the helix bundle (magenta loop, Fig. 3B). This loop, also found in SIRT4 (from Ala194 to Val217), was proposed to mediate protein-protein interaction and substrate-specific binding ( Zhao et al., 2004; Schuetz et al., 2007).

\section{4. $\quad$ Allosteric pockets modulate SIRT catalytic activity}

Allosteric activation is a mechanism mediated by an effector molecule that aims at increasing the protein enzymatic activity. The effector molecule binds to a pocket distinct from the catalytic one, and triggers a conformational change in the protein structure, enabling better binding of the substrate, and hence better activity. The discovery of SIRT1 activation by resveratrol (Howitz et al., 2003) was linked to the beneficial effects of this compound in type 2 diabetes (Milne et al., 2007). In 2015, Cao et al. have managed to crystallise SIRT1 protein in complex with resveratrol and a coumarin-bound peptide acting as substrate (PDB code 5BTR, Table 1 (Cao et al., 2015)). It appears that three resveratrol molecules bind SIRT1 at the entry of the substrate channel. Of those three molecules, two were found to be essential for mediating the interaction between the SIRT1 catalytic core domain and the extended N-terminal domain typical of SIRT1 (Fig. 4). Such interaction allows tighter binding of the co-crystallized SIRT1 peptide substrate, and promotes SIRT1 catalytic activity. Other crystals of SIRT proteins in a complex with a fluorophore-bound peptide and with resveratrol derivatives have been published previously (Table 1). Different behaviours were reported, depending on the isoform and on the molecule studied. The work from Cao et al. supports the idea of an artificial activation of SIRT1 by resveratrol. It seems that the effect of resveratrol depends on the presence of the coumarin moiety of the peptide bonded to SIRT1. Cao et al., by testing the native peptide without coumarin or with an aromatic residue close to the acetylated lysine, did not observe any activation of SIRT1 in vitro (Cao et al., 2015). 
The first X-ray structure of SIRT2 in a complex with the potent and selective SIRT2 drug-like inhibitor SirReal2 was reported. The basis for its high isoform selectivity was proposed to be a ligandinduced structural rearrangement of the active site, exploiting an adjacent, allosteric binding pocket (Rumpf. et al., 2015b). In fact, upon binding of the SirReal2 molecule in the extended C-site (ECS) composed of the $\mathrm{C}$ sub-pocket and of a hydrophobic adjacent area formed by several Phe residues (Phe96, Phe119, Phe190, Phe131, Phe143, Phe234, and Phe235), SIRT2 was found to be locked in an open conformation (Fig. 5). Such a conformation allows the formation of an allosteric pocket behind the ECS, which Rumpf et al. reported as selectivity pocket. This pocket is formed by two loops (from Lys136 to Lys144; from Gly188 to Tyr191) resulting from a 7.2 A rearrangement of a hinge region than connects the Rossmann fold domain with the zinc binding domain (Fig. 5A) (Rumpf. et al., 2015b). Recently, the structural study of a series of indole derivatives in complex with SIRT2 identified the implication of this hinge region in complex stabilization (Rumpf et al., 2015a). In particular, two indole molecules (EX-243) were crystallized in the SIRT2 catalytic site, one of them occupying the selectivity pocket. In this case, one of the loops from the hinge region (from Lys136 to Lys144) was observed to go through a $6 \AA$ shift from the apo conformation (Fig 5B). Interestingly, this selectivity pocket was also able to accommodate long acylated chains such as those characterizing myristoylated substrates (Fig. 5C), explaining the preference of SIRT2 for such peptides characterized by long acylated chains (Feldman et al., 2015).

\section{One-off movements in human SIRT proteins: the gatekeepers}

In addition to loop and domain movements, punctual movements, referred to single amino acids, have been reported in the literature for SIRT proteins. Shifts in side chain orientations actually act as gate keepers, unmasking concealed sub-pockets, and thus influencing the binding of ligands and/or biological partners. Several works described the essential role of a conserved Phe residue from L1 in both SIRT deacetylase and inhibition mechanisms (Fig. S2) (Jin et al., 2009; Zhou et al., 2012; Moniot et al., 2013). This Phe residue when $\mathrm{NAD}^{+}$is present, can adopt a perpendicular side chain conformation with regard to the ribose/nicotinamide moiety, allowing water molecules to enter into the $\mathrm{C}$ sub-pocket, and enabling the release of nicotinamide when cleaved during the reaction. By 
contrast, when only ADP-ribose is present in the pocket, the Phe side chain adopts a parallel conformation compared to the ribose moiety, preventing water molecules from entering the $\mathrm{C}$ subpocket, therefore disabling the base-exchange reaction that causes $\mathrm{NAD}^{+}$regeneration and SIRT inhibition by nicotinamide (Fig. 6A). The role of Phe was also reported very recently by both Gertz et al. and Zhao et al. (Gertz et al., 2013; Zhao et al., 2013). Phe273, interacting with EX-527 in SIRT1, and with other indole derivative molecules in SIRT3 (Phe157), participated in further stabilizing the complexes, thus favouring the inhibition mechanisms of those molecules. The specific conformation adopted by this residue traps the inhibitors in the $\mathrm{C}$ sub-pocket, preventing the release of nicotinamide (Gertz et al., 2013; Zhao et al., 2013).

It is known that the main catalytic activity of SIRTs is deacetylation. However, Du et al. reported that SIRT5 deacetylation activity is very low, compared to the capability of this isoform to de-succinylate and de-malonylate substrates (Du et al., 2011). This specificity towards substrates having chemical groups other than acetyl groups can be correlated with the presence of two residues, Tyr102 and $\operatorname{Arg} 105$, not conserved in other isoforms (Fig. S2), and able to create specific polar contacts with succinylate and de-malonylate substrates (Fig. 6B). In 2012, Fischer et al. showed that insensitivity of SIRT5 to nicotinamide inhibition was the result of Arg105: this residue, pointing towards the C subpocket, prevents the positioning of nicotinamide in the C sub-pocket (Fischer et al., 2012).

\section{Conclusion}

Through the removal of acetyl groups from specific lysine residues and/or through protein-protein interactions, SIRTs are considered as emerging therapeutic targets able to change function and subcellular localization of protein substrates, influencing signaling pathways mainly related to cancer, neurodegeneration, and metabolic diseases. At the time of our data collection, approximately 60 crystallographic structures of human SIRTs, excluding isoforms 4 and 7, were available (Table 1). From their analysis, it appeared that SIRTs are very flexible proteins, undergoing from punctual to massive conformational changes, most of them linked to interactions with molecular partners. The majority of the available SIRT structures revealed information on the catalytic site. Nevertheless, the high structural conservation among catalytic structures has limited the development of isoformselective modulators. Such compounds are necessary not only for understanding isoform-specific 
biological functions, but also for reducing off-target effects of future therapeutics. In our review, we have reported that the flexibility of the catalytic pocket relies, at least in part, on the behavior of L1-L3 loops, that was different in SIRT6 compared to other isoforms. Thus, targeting those loops may lead to locked conformations with a specific effect (increase/decrease) on SIRT catalytic activity. Very recent works on SIRT2 have shed light on catalytic isoform selectivity, by discovering molecules able to bind exclusive sub-pockets whose formation is driven by ligand-induced conformational arrangements. It was also reported that the targeting of allosteric pockets in SIRT1 may be source of selective catalytic modulation. From these observations, it is clear that structural and computational (e.g. molecular dynamics simulation) studies on SIRTs, focusing on protein plasticity, are necessary to identify unexplored structural regions of isoform selectivity.

Indeed, structural information on protein-protein complexes can provide crucial clues about SIRTmediated biological mechanisms, and also ideas for the development of news drugs. Despite the lack of crystallographic data of protein-protein complexes involving SIRTs (Table 1), their zinc binding module has been proposed to mediate such interactions. Investigations on this topic should be now a top priority, first for identifying SIRT protein partners targeting this region, then for determining hotspots for the design of protein-protein disruptors or stabilizers. Further biochemical and conformational works on SIRT $\mathrm{N}$ - and C-terminal domains are also required. As they have been proven to exert a role in regulating SIRT activity, they may be considered as alternative targets for SIRT therapeutic regulation.

\section{Acknowledgements}

AN is grateful to the Excellence fellowship program of the University of Geneva, and to the Swiss National Science Foundation (grant P300P3_158507).

\section{Appendix A. Supplementary data}

Supplementary data associated with this article can be found, in the online version, at XXXX.

\section{References}

N. Ahuja, B. Schwer, S. Carobbio, D. Waltregny, B.J. North, V. Castronovo, P. Maechler, E. Verdin Regulation of insulin secretion by SIRT4, a mitochondrial ADP-ribosyltransferase J. Biol. Chem., 282 (2007), pp. 33583-33592 
K.A. Anderson, M.F. Green, F.K. Huynh, G.R. Wagner, M.D. Hirschey SnapShot: mammalian Sirtuins Cell., 159 (2014), pp. 956-956

X. Bao, Y. Wang, X. Li, X.M. Li, Z. Liu, T. Yang, C.F. Wong, J. Zhang, Q. Hao, X.D. Li Identification of 'erasers' for lysine crotonylated histone marks using a chemical proteomics approach Elife., 3 (2014), pp. 1-18

C.R. Bellamacina The nicotinamide dinucleotide binding motif: a comparison of nucleotide binding proteins FASEB J., 10 (1996), pp. 1257-1269

P. Bheda, H. Jing, C. Wolberger, H. Lin The substrate specificity of Sirtuins Annu. Rev. Biochem., 2 (2016), pp. 405-429

L. Bosch-Presegue, A. Vaquero Sirtuins in stress response: guardians of the genome Oncogene., 33 (2014), pp. 3764-3775

D. Cao, M.Wang, X. Qiu, D. Liu, H. Jiang, N. Yang, and R.M. Xu Structural basis for allosteric, substrate-dependent stimulation of SIRT1 activity by resveratrol Genes Dev., 29 (2015), pp.13161325.

V. Carafa, D. Rotili, M. Forgione, F. Cuomo, E. Serretiello, G.S. Hailu, E. Jarho, M. LahtelaKakkonen, A. Mai, L. Altucci Sirtuin functions and modulation: from chemistry to the clinic Clin.Epigenetics., 8 (2016), pp. 1-21

B. Chen, W. Zang, J. Wang, Y. Huang, Y. He, L. Yan, J. Liu, W. Zheng The chemical biology of Sirtuins Chem. Soc. Rev., 4 (2015), pp. 5246-5264

S. Costantini, A.Sharma, R.Raucci, M.Costantini, I. Autiero, G. Colonna Genealogy of an ancient protein family: the Sirtuins, a family of disordered members BMC Evol. Biol., 13 (2013), pp. 1-19

F. Cubizolles, F. Martino, S. Perrod, S.M. Gasser A homotrimer-heterotrimer switch in Sir2 structure differentiates rDNA and telomeric silencing Mol.Cell., 21 (2006), pp. 825-836

H. Dai, A.W. Case, T.V. Riera, T. Considine, J.E. Lee, Y. Hamuro, H. Zhao, Y. Jiang, S.M. Sweitzer, B.Pietrak, B. Schwartz, C.A. Blum, J.S. Disch, R. Caldwell, B. Szczepankiewicz, C. Oalmann, P. Yee Ng, B.H. White, R. Casaubon, R. Narayan, K. Koppetsch, F. Bourbonais, B. Wu, J. Wang, D. Qian, F. Jiang, C. Mao, M.Wang, E. Hu, J.C. Wu, R.B. Perni, G.P. Vlasuk, J.L. Ellis Crystallographic structure of a small molecule SIRT1 activator-enzyme complex Nat. Commun., 6 (2015), pp. 1-10

A.M. Davenport, F.M. Huber, A. Hoelz Structural and functional analysis of human SIRT1 J. Mol. Biol., 426 (2014), pp. 526-541

J.S. Disch, G. Evindar, C.H. Chiu, C.A. Blum, H. Dai, L. Jin, E. Schuman, K.E. Lind, S.L. Belyanskaya, J. Deng, F. Coppo, L. Aquilani, T.L. Graybill, J.W. Cuozzo, S. Lavu, C. Mao, G.P. Vlasuk, R.B. Perni Discovery of thieno[3,2-d]pyrimidine-6-carboxamides as potent inhibitors of SIRT1, SIRT2, and SIRT3 J. Med. Chem., 56 (2013), pp.3666-3679

J. Du, Y. Zhou, X. Su, J.J. Yu, S. Khan, H. Jiang, J. Kim, J.Woo, J.H. Kim, B.H. Choi, B. He, W. Chen, S. Zhang, R.A. Cerione, J. Auwerx, Q. Hao, H. Lin SIRT5 is a NAD-dependent protein lysine demalonylase and desuccinylase Science., 334 (2011), pp.806-809

S. Ehrentraut, M. Hassler, M. Oppikofer, S. Kueng, J.M. Weber, J.W. Mueller, S.M. Gasser, A.G. Ladurner, A.E. Ehrenhofer-Murray Structural basis for the role of the Sir3 AAA+ domain in silencing: interaction with Sir4 and unmethylated histone H3K79 Genes Dev., 25 (2011), pp. 1835-1846 
J.L. Feldman, K.E. Dittenhafer-Reed, N. Kudo, J.N. Thelen, A. Ito, M. Yoshida, J.M. Denu Kinetic and structural basis for acyl-groupselectivity and NAD+ dependence in Sirtuin-catalyzed deacylation Biochemistry., 54 (2015), pp. 3037-3050

M.S. Finnin, J.R. Donigian, N.P. Pavletich Structure of the histone deacetylase SIRT2 Nat. Struct. Biol., 8 (2001), pp. 621-625

Fischer F., M. Gertz, B. Suenkel, M. Lakshminarasimhan, M. Schutkowski, C. Steegborn Sirt5 deacylation activities show differential sensitivities to nicotinamide inhibition Plos One., 7 (2001), pp. e 45098

R.A. Frye Characterization of five human cDNAs with homology to the yeast SIR2 gene: Sir2like proteins (Sirtuins) metabolize NAD and may have protein ADP-ribosyltransferase activity Biochem. Biophys. Res.Commun., 260 (1999), pp. 273-279

R.A. Frye Phylogenetic classification of prokaryotic and eukaryotic sir2-like proteins Biochem. Biophys. Res. Commun., 273 (2000), pp. 793-798

M. Gertz, F. Fischer, G.T.T. Nguyen, M. Lakshminarasimhan, M. Schutkowski, M. Weyand, C. Steegborn Ex-527 inhibits Sirtuins by exploiting their unique $\mathrm{NAD}^{+}$-dependent deacetylation mechanism Proc. Natl. Acad. Sci., 110 (2013), pp. E2772-E2781

M. Gertz, G.T.T. Nguyen, F. Fischer, B. Suenkel, C. Schlicker, B. Fränzel, J. Tomaschewski, F. Aladini, C. Becker, D. Wolters, C. Steegborn A molecular mechanism for direct sirtuin activation by resveratrol Plos One., 7 (2012), pp. e49761

S.G. Gray, T.J.Ekström The human histone deacetylase family Exp. Cell. Res., 262 (2001), pp. 7583

A. Grob, P.Roussel, J.E.Wright, B.McStay, D.Hernandez-Verdun, V.Sirri Involvement of SIRT7 in resumption of rDNA transcription at the exit from mitosis J. Cell Sci., 122 (2009), pp. 489-498

K.T. Howitz, K.J. Bitterman, H.Y. Cohen, D.W. Lamming, S. Lavu, J.G. Wood, R.E. Zipkin, P. Chung, A. Kisielewski, L.L. Zhang, B. Scherer, D.A. Sinclair Small molecule activators of sirtuins extend Saccharomyces cerevisiae lifespan Nature., 425 (2003), pp. 191-196

S. Imai, C.M. Armstrong, M. Kaeberlein, L. Guarente Transcriptional silencing and longevity protein Sir2 is an NAD-dependent histone deacetylase Nature., 403 (2000), pp. 795-800

H. Jiang, S. Khan, Y. Wang, G. Charron, B. He, C. Sebastian, J. Du, R. Kim, E. Ge, R. Mostoslavsky, H.C. Hang, Q. Hao, H. Lin SIRT6 regulates TNF- $\alpha$ secretion through hydrolysis of long-chain fatty acyl lysine Nature., 496 (2013), pp. 110-113

L. Jin, W. Wei, Y. Jiang, H. Peng, J. Cai, C. Mao, H. Dai, W. Choy, J.E. Bemis, M.R. Jirousek, J.C. Milne, C.H. Westphal, R.B. Perni Crystal structures of human SIRT3 displaying substrateinduced conformational changes J. Biol. Chem., 284 (2009), pp. 24394-24405

L.M. Johnson, P.S.Kayne, E.S.Kahn, M.Grunstein Genetic-evidence for an interaction between Sir3 and histone-H4 in the repression of the silent mating loci in Saccharomyces-cerevisiae Proc. Natl. Acad. Sci. USA., 87 (1990), pp. 6286-6290

H. Kang, J.Y. Suh, Y.S. Jung, J.W. Jung, M.K. Kim, J.H. Chung Peptide switch is essential for SIRT1 deacetylase activity Mol. Cell., 44 (2001), pp. 203-213

S.J. Lin, E. Ford, M. Haigis, G. Liszt, L. Guarente Calorie restriction extends yeast life span by lowering the level of NADH Genes Dev., 18 (2004), pp 12-16 
A.B. Mariotto, K.R. Yabroff, Y. Shao, E.J. Feuer, M.L. Brown Projections of the cost of cancer care in the United States: 2010-2020 J. Nat. Cancer Inst., 103 (2011), pp. 117-128

P. Mellini, S. Valente, A. Mai Sirtuin modulators: an updated patent review (2012-2014) Expert Opin. Ther. Pat., 25 (2015), pp. 5-15

E. Michishita, J.Y. Park, J.M. Burneskis, J.C. Barrett, I. Horikawa Evolutionarily conserved and nonconserved cellular localizations and functions of human SIRT proteins Mol. Biol. Cell., 16 (2005), pp. 4623-4635

J.C. Milne, P.D. Lambert, S. Schenk, D.P. Carney, J.J. Smith, D.J. Gagne, L. Jin, O. Boss, R.B. Perni, C.B. Vu, J.E. Bemis, R. Xie, J.S. Disch, P.Y. Ng, J.J. Nunes, A.V. Lynch, H. Yang, H. Galonek, K. Israelian, W. Choy, A. Iffland, S. Lavu, O. Medvedik, D.A. Sinclair, J.M. Olefsky, M.R. Jirousek, P.J. Elliott, C.H. Westphal Small molecule activators of SIRT1 as therapeutics for the treatment of type 2 diabetes Nature., 450 (2007), pp. 712-716

S. Moniot, M. Schutkowski, J. Steegborn Crystal structure analysis of human SIRT2 and its ADPribose complex J. Struct. Biol., 182 (2013), pp. 136-143

G.A. Murphy, E.J. Spedale, S.T. Powell, L. Pillus, S.C. Schultz, L. Chen The Sir4 C-terminal coiled coil is required for telomeric and mating type silencing in Saccharomyces cerevisiae J. Mol. Biol., 334 (2013), pp. 769-780

G.T. Nguyen, M. Gertz, C. Steegborn Crystal structures of Sirt3 complexes with 4'-bromoresveratrol reveal binding sites and inhibition mechanism Chem. Biol., 20 (2013a), pp. 1375-1385

G.T. Nguyen, S. Schaefer, M. Gertz, M. Weyand, C. Steegborn Structures of human sirtuin 3 complexes with ADP-ribose and with carba-NAD ${ }^{+}$and SRT1720: binding details and inhibition mechanism Acta Crystallogr. D Biol. Crystallogr., 69 (2013b), pp. 1423-1432

B.J. North, B.L. Marshall, M.T. Borra, J.M. Denu, E. Verdin The human Sir2 ortholog, SIRT2, is an NAD(+)-dependent tubulin deacetylase Mol. Cell., 11 (2003), pp. 437-444

B.J. North, E. Verdin Mitotic regulation of SIRT2 by cyclin-dependent kinase 1-dependent phosphorylation J. Biol. Chem., 282 (2007), pp. 19546-19555

P. Onyango, I. Celic, J.M. McCaffery, J.D. Boeke, A.P. Feinberg SIRT3, a human SIR2 homologue, is an NAD-dependent deacetylase localized to mitochondria Proc. Natl. Acad. Sci. USA., 99 (2002), pp. 13653-13658

M. Oppikofer, S. Kueng, S.M. Gasser SIR-nucleosome interactions: structure-function relationships in yeast silent chromatin. Gene., 527 (2013), pp. 10-25

P.W. Pan, J.L. Feldman, M.K. Devries, A. Dong, A.M. Edwards, J.M. Denu Structure and biochemical functions of SIRT6 J. Biol. Chem., 286 (2011), pp. 14575-14587

R. Pandithage, R. Lilischkis, K. Harting, A. Wolf, B. Jedamzik, J. Lüscher-Firzlaff, J. Vervoorts, E. Lasonder, E. Kremmer, B. Knöll, B. Lüscher The regulation of SIRT2 function by cyclindependent kinases affects cell motility J. Cell. Biol., 180 (2008), pp. 915-929

C. Peng, Z. Lu, Z. Xie, Z. Cheng, Y. Chen, M. Tan, H. Luo, Y. Zhang, W. He, K. Yang, B.M. Zwaans, D. Tishkoff, L. Ho, D. Lombard, T.C. He, J. Dai, E. Verdin, Y. Ye, Y. Zhao The first identification of lysine malonylation substrates and its regulatory enzyme Mol. Cell. Proteomics., 10 (2011), pp. M111. 012658 
J. Rine, I. Herskowitz Four genes responsible for a position effect on expression from HML and HMR in Saccharomyces cerevisiae Genetics., 116 (1987), pp. 9-22

T. Rumpf, S. Gerhardt, O. Einsle, M. Jung Seeding for sirtuins: microseed matrix seeding to obtain crystals of human Sirt3 and Sirt2 suitable for soaking Acta Crystallogr. F Struct. Biol. Commun., 71 (2015a), pp. 1498-1510

T. Rumpf, M. Schiedel, B. Karaman, C. Roessler, B.J. North, A. Lehotzky, J. Oláh, K.I. Ladwein, K. Schmidtkunz, M. Gajer, M. Pannek, C. Steegborn, D.A. Sinclair, S. Gerhardt, J. Ovádi, M. Schutkowski, W. Sippl, O. Einsle, M. Jung Selective Sirt2 inhibition by ligand-induced rearrangement of the active site Nat. Commun., 6 (2015b), pp. 1-13

S. Sakkiah, M. Arooj, G.P. Cao, K.W. Lee Insight the C-site pocket conformational changes responsible for sirtuin 2 activity using molecular dynamics simulations Plos One., 8 (2013a), pp. e59278

S. Sakkiah, M. Arooj, M.R. Kumar, S.H. Eom, K.W. Lee Identification of inhibitor binding site in human sirtuin 2 using molecular docking and dynamics simulations Plos One., 8 (2013b), pp. e51429

S. Sakkiah, M. Chandrasekaran, Y. Lee, S. Kim, K.W. Lee Molecular modeling study for conformational changes of Sirtuin 2 due to substrate and inhibitor binding J. Biomol. Struct. Dyn., 30 (2012), pp. 235-254

M. Schiedel, T. Rumpf, B. Karaman, A. Lehotzky, J.O. Gerhardt, J. Ovádi, W. Sippl, O. Einsle, M. Jung Structure-Based Development of an Affinity Probe for Sirtuin 2 Angew. Chem. Int. Ed. Engl., 55 (2016a), pp. 2252-2256

M. Schiedel, T. Rumpf, B. Karaman, A. Lehotzky, J. Oláh, S. Gerhardt, J. Ovádi, W. Sippl, O. Einsle, M. Jung Aminothiazoles as Potent and Selective Sirt2 Inhibitors: A Structure-Activity Relationship Study J. Med. Chem., 59 (2016b), pp. 1599-1612

A. Schuetz, J. Min, T. Antoshenko, C.L. Wang, A. Allali-Hassani, A. Dong, P. Loppnau, M. Vedadi, A. Bochkarev, R. Sternglanz, A.N. Plotnikov Structural basis of inhibition of the human NAD ${ }^{+}$ dependent deacetylase SIRT5 by suramin Structure., 15 (2007), pp.377-389

B.G. Szczepankiewicz., H. Dai, K.J. Koppetsch, D. Qian, F. Jiang, C. Mao, R.B. Perni Synthesis of Carba-NAD and the structures of its ternary complexes with SIRT3 and SIRT5 J. Org. Chem., 77 (2012), pp. 7319-7329

K.G. Tanner, J. Landry, R. Sternglanz, J.M. Denu Silent information regulator 2 family of NADdependent histone/protein deacetylases generates a unique product, 1-O-acetyl-ADP-ribose Proc. Natl. Acad. Sci. USA., 97 (2000), pp. 14178-14182

Y.B. Teng, H. Jing, P. Aramsangtienchai, B. He, S. Khan, J. Hu, H.Lin, Q. Hao Efficient demyristoylase activity of SIRT2 revealed by kinetic and structural studies Sci. Rep., 5 (2015), pp. 1-8

A. Vaquero, D. Reinberg Calorie restriction and the exercise of chromatin Genes Dev., 23 (2009), pp. 1849-1869

J.M. Villalba, R. de Cabo, F.J. Alcain A patent review of sirtuin activators: an update Exp. Opin. Ther. Pat., 22 (2012), pp. 355-367 
J. Wu, D. Zhang, L. Chen, J. Li, J. Wang, C. Ning, N. Yu, F. Zhao, D. Chen, X. Chen, K. Chen, H. Jiang, H. Liu, D. Liu Discovery and mechanism study of SIRT1 activators that promote the deacetylation of fluorophore-labeled substrate J. Med. Chem., 56 (2013), pp. 761-780

K. Yamagata, Y. Goto, H. Nishimasu, J. Morimoto, R. Ishitani, N. Dohmae, N. Takeda, R. Nagai, I. Komuro, H.Suga, O. Nureki Structural basis for potent inhibition of SIRT2 deacetylase by a macrocyclic peptide inducing dynamic structural change Structure., 22 (2014), pp. 345-352

K. Zhao, X. Chai, R. Marmorstein Structure and substrate binding properties of cobB, a Sir2 homolog protein deacetylase from Escherichia coli J. Mol. Biol., 337 (2004), pp. 731-741

X. Zhao, D. Allison, B. Condon, F. Zhang, T. Gheyi, A. Zhang, S. Ashok, M. Russell, I. MacEwan, Y. Qian, J.A. Jamison, J.G. Luz The 2.5A Crystal Structure of the SIRT1 Catalytic Domain Bound to Nicotinamide Adenine Dinucleotide $\left(\mathrm{NAD}^{+}\right)$and an Indole (EX527 Analogue) Reveals a Novel Mechanism of Histone Deacetylase Inhibition J. Med. Chem. 56 (2013), pp. 963-969

Y. Zhou, H. Zhang, B. He, J. Du, H. Lin, R.A. Cerione, Q. Hao The bicyclic intermediate structure provides insights into the desuccinylation mechanism of human sirtuin 5 (SIRT5) J. Biol. Chem., 287 (2012), pp. 28307-28314 


\section{Figure captions}

Fig.1. Schematic representation (topology) of the seven human SIRT isoforms. N-terminal, catalytic, and C-terminal domains are represented in light blue, brown, and light green, respectively. The amino acid (aa) length of each domain is also reported.

Fig.2. Overall three-dimensional (3D) structure of SIRTs, and details on the structural organisation of the SIRT catalytic domain. SIRT2 structure is taken as an example (A). Flexible loops that undergo massive changes upon substrate binding are highlighted according to the legend (B). Structural comparison between SIRT2 and SIRT6: the helical module in SIRT6 is missing (C). The loop inserted in the SIRT6 zinc-binding module is coloured in red, and the myristoylated peptide co-crystallised with SIRT6 is represented in black capped sticks. Proteins are represented by ribbons, coloured according to the legend. Catalytic sub-pocket areas are represented as coloured surfaces. Images are generated using MOE 2014.09 (Chemical Computing Group, Inc., Montreal, Canada).

Fig.3. SIRT2 (A) and SIRT5 (B) loops involved in isoform-specific protein-protein interactions. Proteins are represented by ribbons. Loops are coloured as described in the text. Helical and zinc binding modules of each isoform are coloured in brown and blue, respectively. The large domain of each protein is coloured in light grey. Images are generated using MOE 2014.09 (Chemical Computing Group, Inc., Montreal, Canada).

Fig. 4. Overall structure of SIRT1 in complex with a coumarin-bound peptide and resveratrol molecules (PDB code 5BTR). The large domain, the zinc binding, and the helical modules of SIRT1 are represented by grey, blue, and brown ribbons, respectively. The same colour code is used for molecular surfaces. The N-terminal domain of SIRT1 implicated in allosteric regulation is represented by light pink ribbons. Peptide bound to a coumarin fluorophore is represented by magenta line and balls. Resveratrol molecules 1, 2, and 3 are reported in capped sticks and coloured in cyan, yellow, and dark green, respectively. Amino acids important for interactions with resveratrol molecules are represented by line and balls, and coloured according to SIRT1 domains colour code. Images are generated using MOE 2014.09 (Chemical Computing Group, Inc., Montreal, Canada).

Fig. 5. Overall SIRT2 structure, with a focus on hinge region movements formed upon the binding of SirReal2 (A), EX-243 (B), and of the myristoylated peptide substrate (C). Proteins are represented by ribbons and coloured according to the legend. Inhibitors and substrates are represented by ball and lines and coloured according to the legend. Amino acids belonging to the ECS site and to the selectivity pocket (from Lys133 to Lys144; from Gly188 to Tyr191) are represented by capped sticks and line and balls, respectively. Images are generated using MOE 2014.09 (Chemical Computing Group, Inc., Montreal, Canada).

Fig. 6. Phe 96 acts as a gate keeper in SIRT2 (A). When ADP-ribose, represented by magenta purple line and balls, interacts with SIRT2, Phe96 is able to trap nicotinamide (yellow line and balls) in the C sub-pocket. Tyr102 and Arg105 are responsible for succinylate and de-malonylate activities in SIRT5 (B). C sub-pocket and a $\mathrm{NAD}^{+}$molecule are highlighted in the pocket. Images are generated using MOE 2014.09 (Chemical Computing Group, Inc., Montreal, Canada). 


\section{Tables}

Table 1 Review of human SIRT structures reported in the PDB (http://www.rcsb.org/, accessed: June $\left.17^{\text {th }}, 2016\right)$.

\begin{tabular}{|c|c|c|c|c|}
\hline SIRT isoform & PDB code & Ligand & Resolution & Reference \\
\hline \multirow{8}{*}{ SIRT1 } & $4 \mathrm{I} 5 \mathrm{I}$ & $\begin{array}{c}\mathrm{NAD}^{+} \\
\text {6S-2-chloro-5,6,7,8,9,10- } \\
\text { hexahydrocyclohepta[b]indole-6-carboxamide }\end{array}$ & $2.50 \AA$ & $\begin{array}{l}\text { (Zhao et al., } \\
\text { 2013) }\end{array}$ \\
\hline & 4IF6 & ADP-ribose & $2.25 \AA$ & NA \\
\hline & 4KXQ & ADP-ribose & $1.85 \AA$ & (Davenport $e t$ \\
\hline & 4IG9 & - & $2.64 \AA$ & al., 2014) \\
\hline & 5BTR & $\begin{array}{c}\text { Resveratrol } \\
\text { AMC-containing peptide }\end{array}$ & $3.20 \AA$ & $\begin{array}{l}\text { (Cao et al., } \\
\text { 2015) }\end{array}$ \\
\hline & $4 \mathrm{ZZH}$ & $\begin{array}{c}\text { (4S)-N-[3-(1,3-oxazol-5-yl)phenyl]-7-[3- } \\
\text { (trifluoromethyl)phenyl]- 3,4-dihydro-1,4- } \\
\text { methanopyrido[2,3-b][1,4]diazepine- } 5(2 \mathrm{H}) \text { - } \\
\text { carboxamide }\end{array}$ & $3.10 \AA$ & \multirow{3}{*}{$\begin{array}{l}\text { (Dai et al., } \\
\text { 2015) }\end{array}$} \\
\hline & $4 Z Z I$ & $\begin{array}{l}\text { 4-(4-\{2-[(methylsulfonyl)amino]ethyl }\} \text { piperidin- } \\
\text { 1-yl)thieno[3,2-d]pyrimidine-6-carboxamide }\end{array}$ & $2.73 \AA$ & \\
\hline & $4 \mathrm{ZZJ}$ & $\begin{array}{l}\text { (3S)-1,3-dimethyl-N-[3-(1,3-oxazol-5-yl)phenyl]- } \\
\text { 6-[3-(trifluoromethyl)phenyl]-2,3- } \\
\text { dihydropyrido[2,3- b]pyrazine-4(1H)-carboxamide }\end{array}$ & $2.74 \AA$ & \\
\hline \multirow{16}{*}{ SIRT2 } & $1 \mathrm{~J} 8 \mathrm{~F}$ & - & $1.70 \AA$ & $\begin{array}{l}\text { (Finnin et al., } \\
\text { 2001) }\end{array}$ \\
\hline & $3 Z G V$ & $\mathrm{NAD}^{+}$ & $2.27 \AA$ & (Moniot et \\
\hline & $3 Z G O$ & - & $1.63 \AA$ & al., 2013) \\
\hline & $4 \mathrm{~L} 3 \mathrm{O}$ & Macrocyclic peptide (S2iL5) & $2.52 \AA$ & $\begin{array}{c}\text { (Yamagata } e t \\
\text { al., 2014) }\end{array}$ \\
\hline & $4 \mathrm{RMG}$ & $\begin{array}{c}\text { 2-[(4,6-dimethylpyrimidin-2-yl)sulfanyl]- N-[5- } \\
\text { (naphthalen-1-ylmethyl)-1,3-thiazol- 2- } \\
\text { yl]acetamide (Sir2real) }\end{array}$ & $1.88 \AA$ & \multirow{4}{*}{$\begin{array}{l}\text { (Rumpf,T. et } \\
\text { al., 2015b) }\end{array}$} \\
\hline & 4RMH & $\begin{array}{c}\text { Sir2real } \\
\text { Ac-Lys-H3 peptide }\end{array}$ & $1.42 \AA$ & \\
\hline & 4RMI & $\begin{array}{c}\text { N-(5-benzyl-1,3-thiazol-2-yl)-2-[(4,6- } \\
\text { dimethylpyrimidin- 2-yl)sulfanyl]acetamide } \\
\text { (Sir1real) }\end{array}$ & $1.45 \AA$ & \\
\hline & $4 \mathrm{RMJ}$ & $\begin{array}{c}\text { ADP-ribose } \\
\text { Nicotinamide }\end{array}$ & $1.87 \AA$ & \\
\hline & $4 \mathrm{R} 8 \mathrm{M}$ & Thiomyristoyl peptide & $2.10 \AA$ & $\begin{array}{l}\text { (Teng } \text { et al., } \\
\text { 2015) }\end{array}$ \\
\hline & $5 \mathrm{D} 7 \mathrm{O}$ & ADP-ribose & $1.63 \AA$ & \multirow{3}{*}{$\begin{array}{l}\text { (Rumpf,T. et } \\
\text { al., 2015a) }\end{array}$} \\
\hline & $5 \mathrm{D} 7 \mathrm{P}$ & $\begin{array}{l}\text { ADP-ribose } \\
\text { EX-243 }\end{array}$ & $1.76 \AA$ & \\
\hline & $5 \mathrm{D} 7 \mathrm{Q}$ & $\begin{array}{c}\text { ADP-ribose } \\
\text { (6S)-2-chloro-5,6,7,8,9,10- } \\
\text { hexahydrocyclohepta[b]indole-6-carboxamide }\end{array}$ & $2.01 \AA$ & \\
\hline & 4Y6L & H3K9 myristoylated & $1.6 \AA$ & \multirow{3}{*}{$\begin{array}{l}\text { (Feldman et } \\
\text { al., 2015) }\end{array}$} \\
\hline & $4 \mathrm{Y} 6 \mathrm{O}$ & TNF- $\alpha$ K20 myristoylated & $1.6 \AA$ & \\
\hline & 4Y6Q & 2-O-myristoyl-ADP-ribose & $1.9 \AA$ & \\
\hline & $4 \mathrm{X} 3 \mathrm{O}$ & 2-O-myristoyl-ADP-ribose & $1.5 \AA$ & NA \\
\hline
\end{tabular}




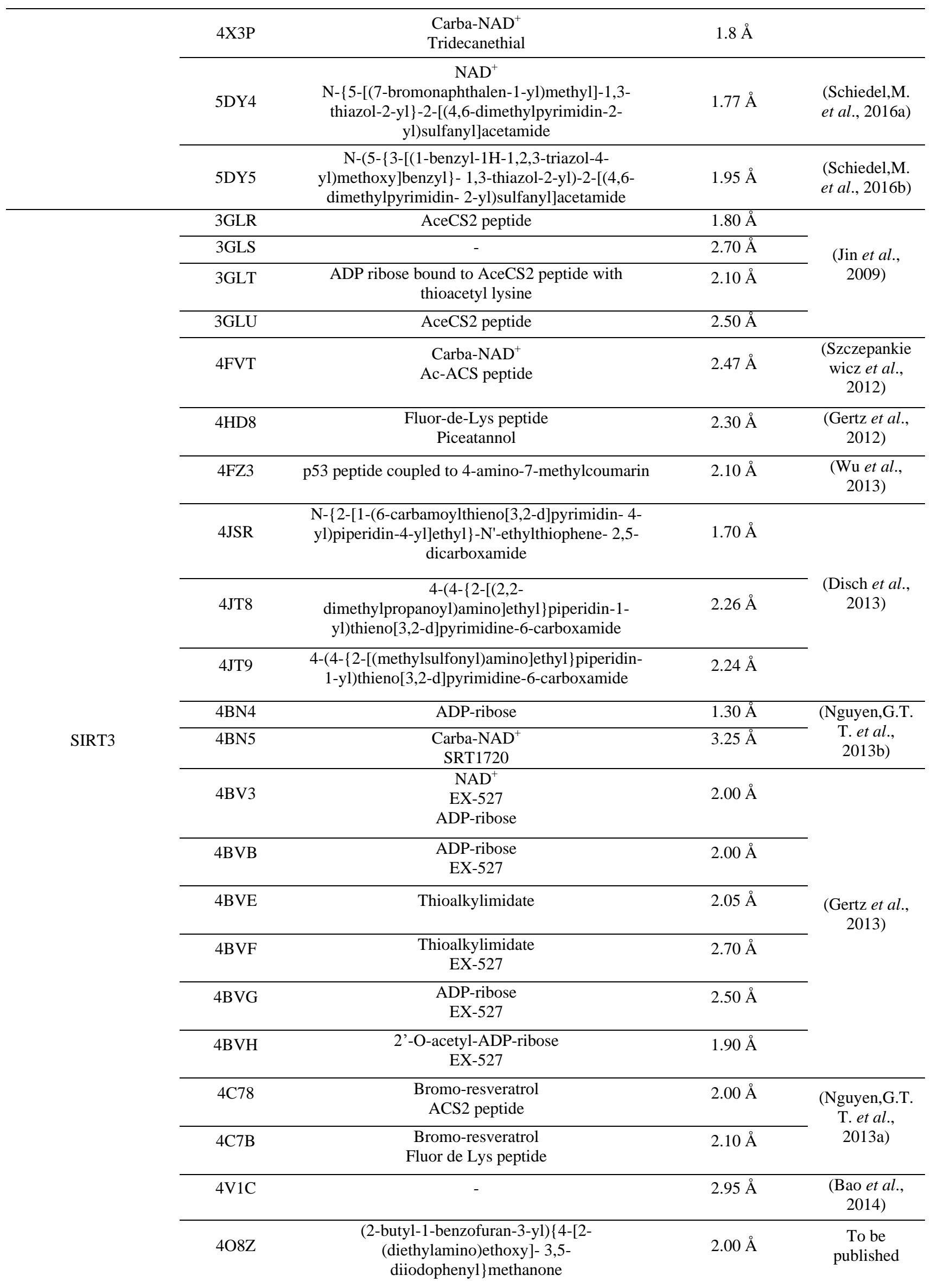




\begin{tabular}{|c|c|c|c|c|}
\hline & $5 \mathrm{D} 7 \mathrm{~N}$ & - & $1.83 \AA$ & $\begin{array}{c}\text { (Rumpf,T. et } \\
\text { al., 2015a) }\end{array}$ \\
\hline \multirow{8}{*}{ SIRT5 } & 2B4Y & $\begin{array}{c}\text { ADP-ribose } \\
\text { 4-(2-Hydroxyethyl)-1-piperazine ethansulfonic } \\
\text { acid }\end{array}$ & $1.90 \AA$ & NA \\
\hline & $2 \mathrm{NYR}$ & Suramin & $2.06 \AA$ & $\begin{array}{l}\text { (Schuetz et } \\
\text { al., 2007) }\end{array}$ \\
\hline & 3RIG & Thioacetylated lysine peptide & $2.00 \AA$ & \multirow{2}{*}{$\begin{array}{c}\text { (Du et al., } \\
\text { 2011) }\end{array}$} \\
\hline & $3 R I Y$ & $\begin{array}{c}\text { NAD }^{+} \\
\text {Succinyl lysine peptide }\end{array}$ & $1.55 \AA$ & \\
\hline & 4F4U & Succinyl lysine peptide & $2.00 \AA$ & \multirow{2}{*}{$\begin{array}{c}\text { (Zhou et al., } \\
\text { 2012) }\end{array}$} \\
\hline & 4F56 & ADP ribose bound to thiosuccinyl peptide & $1.70 \AA$ & \\
\hline & $4 \mathrm{GC} 1$ & $\begin{array}{c}\text { Succinyl-IDH2 } \\
\text { Carba-NAD }\end{array}$ & $1.94 \AA$ & $\begin{array}{l}\text { (Szczepankie } \\
\text { wicz } \text { et al., } \\
\text { 2012) }\end{array}$ \\
\hline & 4HDA & $\begin{array}{l}\text { Acetylated peptide } \\
\text { Resveratrol }\end{array}$ & $2.60 \AA$ & $\begin{array}{c}\text { (Gertz et al., } \\
\text { 2012) }\end{array}$ \\
\hline \multirow{4}{*}{ SIRT6 } & $3 \mathrm{~K} 35$ & ADP-ribose & $2.00 \AA$ & \multirow{3}{*}{$\begin{array}{l}\text { (Pan et al., } \\
\text { 2011) }\end{array}$} \\
\hline & 3PKI & ADP-ribose & $2.04 \AA$ & \\
\hline & 3PKJ & 2'-N-Acetyl-ADP-ribose & $2.12 \AA$ & \\
\hline & $3 Z$ G6 & $\begin{array}{c}\text { ADP-ribose } \\
\text { N6-myristoyl lysine peptide }\end{array}$ & $2.20 \AA$ & $\begin{array}{l}\text { (Jiang et al., } \\
\text { 2013) }\end{array}$ \\
\hline
\end{tabular}




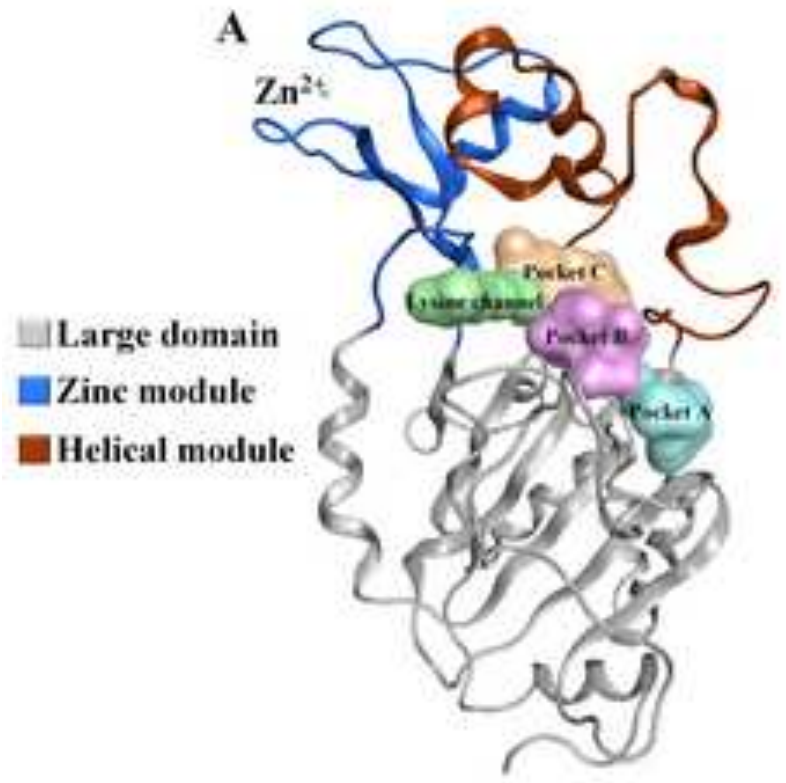

SIRT2

PDB code 3ZGV

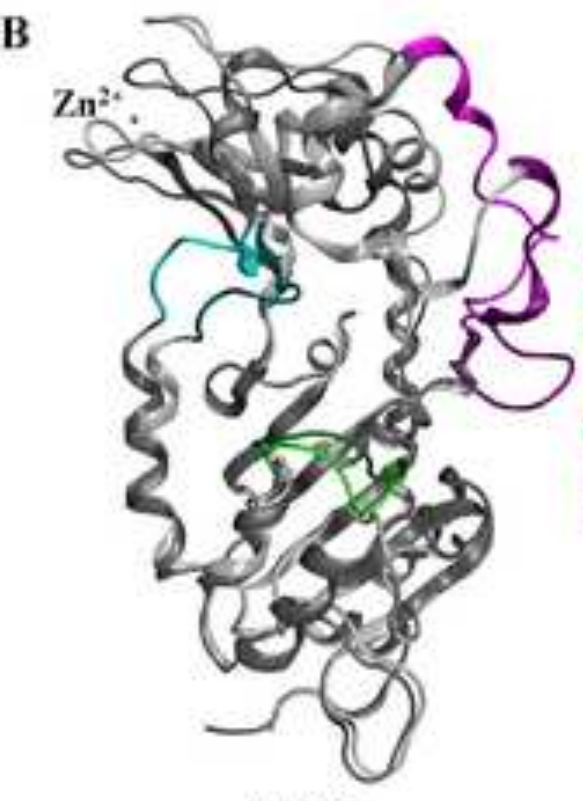

SIRT2

PDB code 1.JF8 (dark grey, apo-form)

PDB code 3ZGV (light grey, productive form)

C

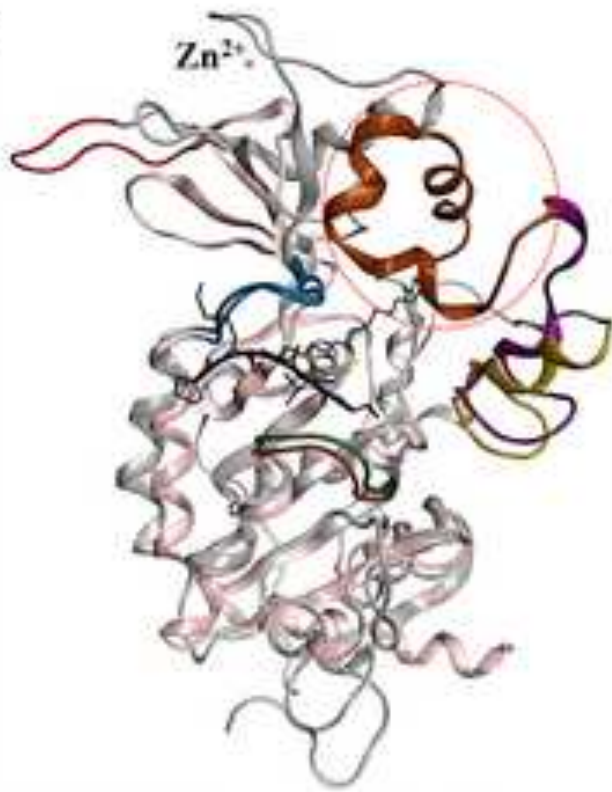

Loop 1 SIRT2

Loop 1 SIRT6

든op 2 SIRT2

- LLoop 2 SIRT6

- Loop 3 SIRT2

- Loop 3 SIRT6

SIRT2 (PDB code 3ZGV, light grey) SIRT6 (PDB code 3PKI, light pink) 


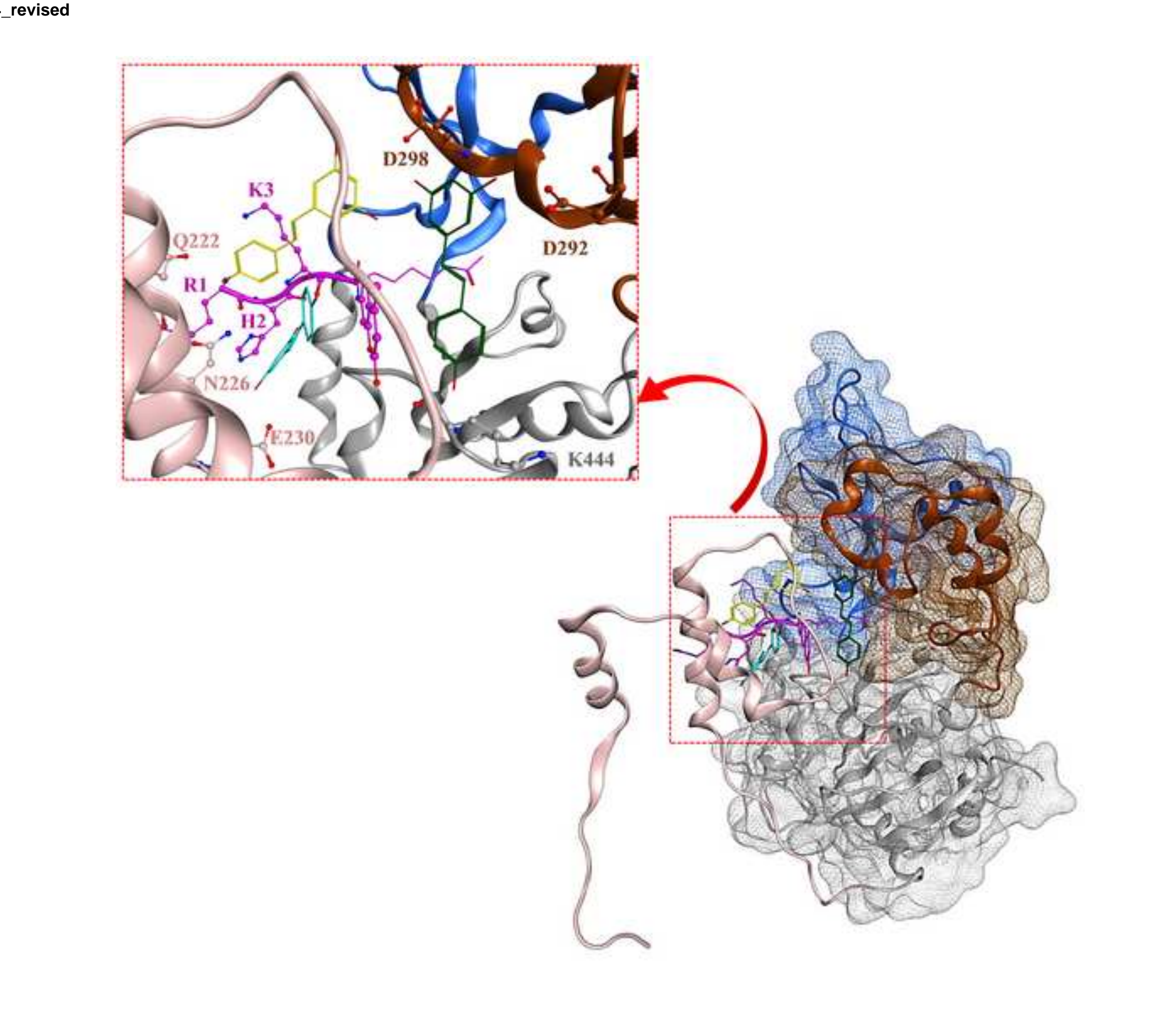


A

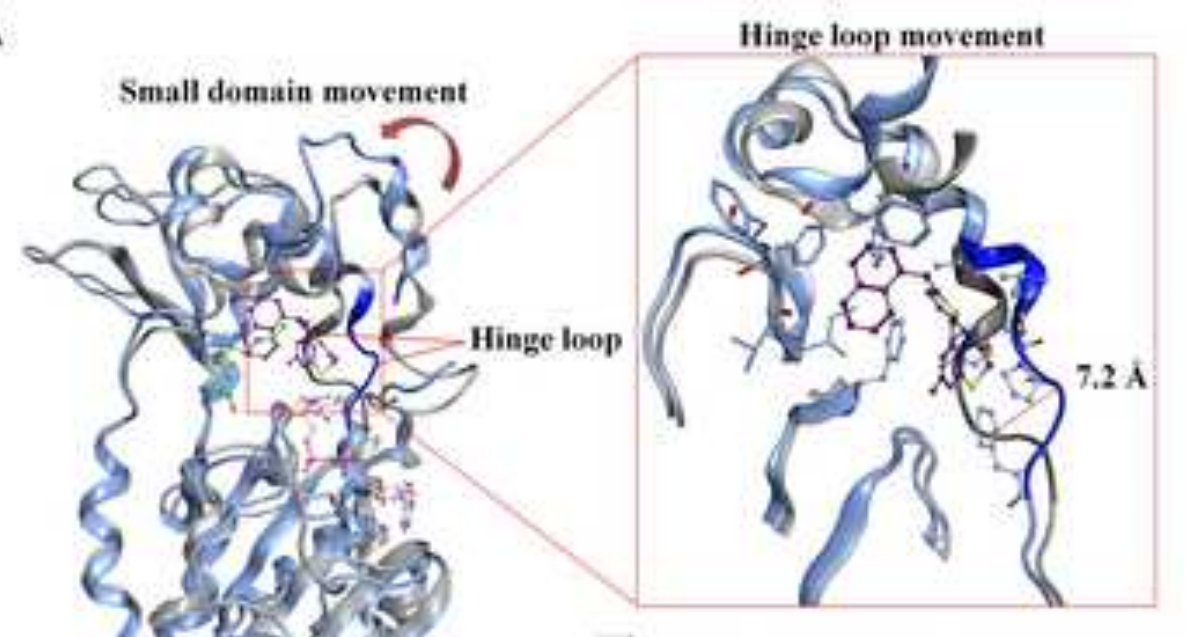

4 SIKT2 - productive form (PDB code 5D7O)

$2 \operatorname{SIRT2}-\mathrm{NAD}^{2}-$ Sirkeal2 (PDB code ARNG)

$\checkmark$ NAD $^{*}$ (PDB cole 4RNG)

Ae-Lys-H3 peptide (PDB colle 4RMH)

- SirReal2 (PDB code ARMG)

C.

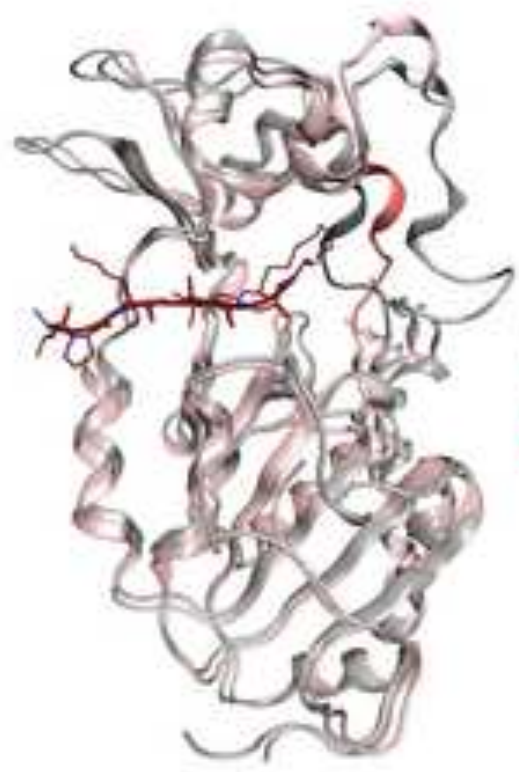

B

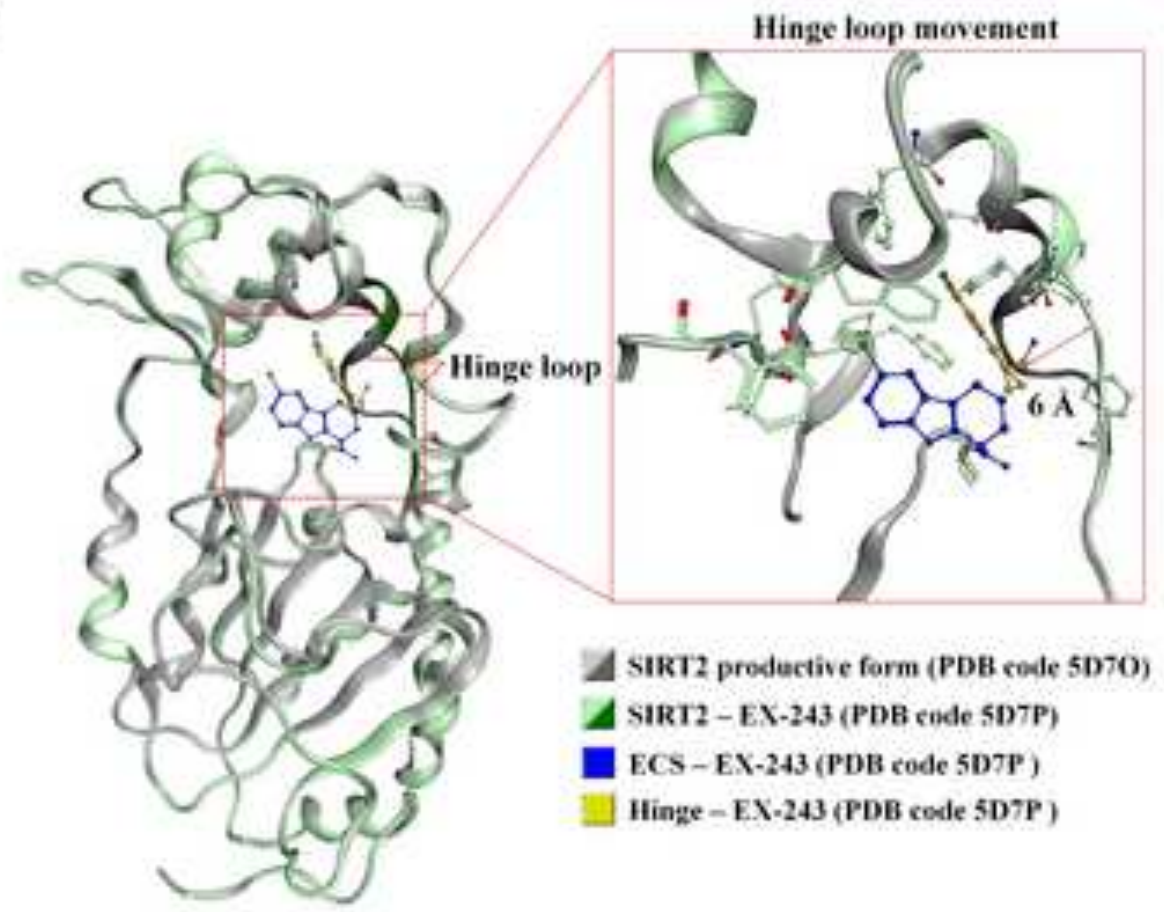

A SIRT2 productive form (PDB ende 5D7O) 4 SIRT2 (PDE code 4V6O)

Myristay lated sabatrate (PDB code 4Y6O) 

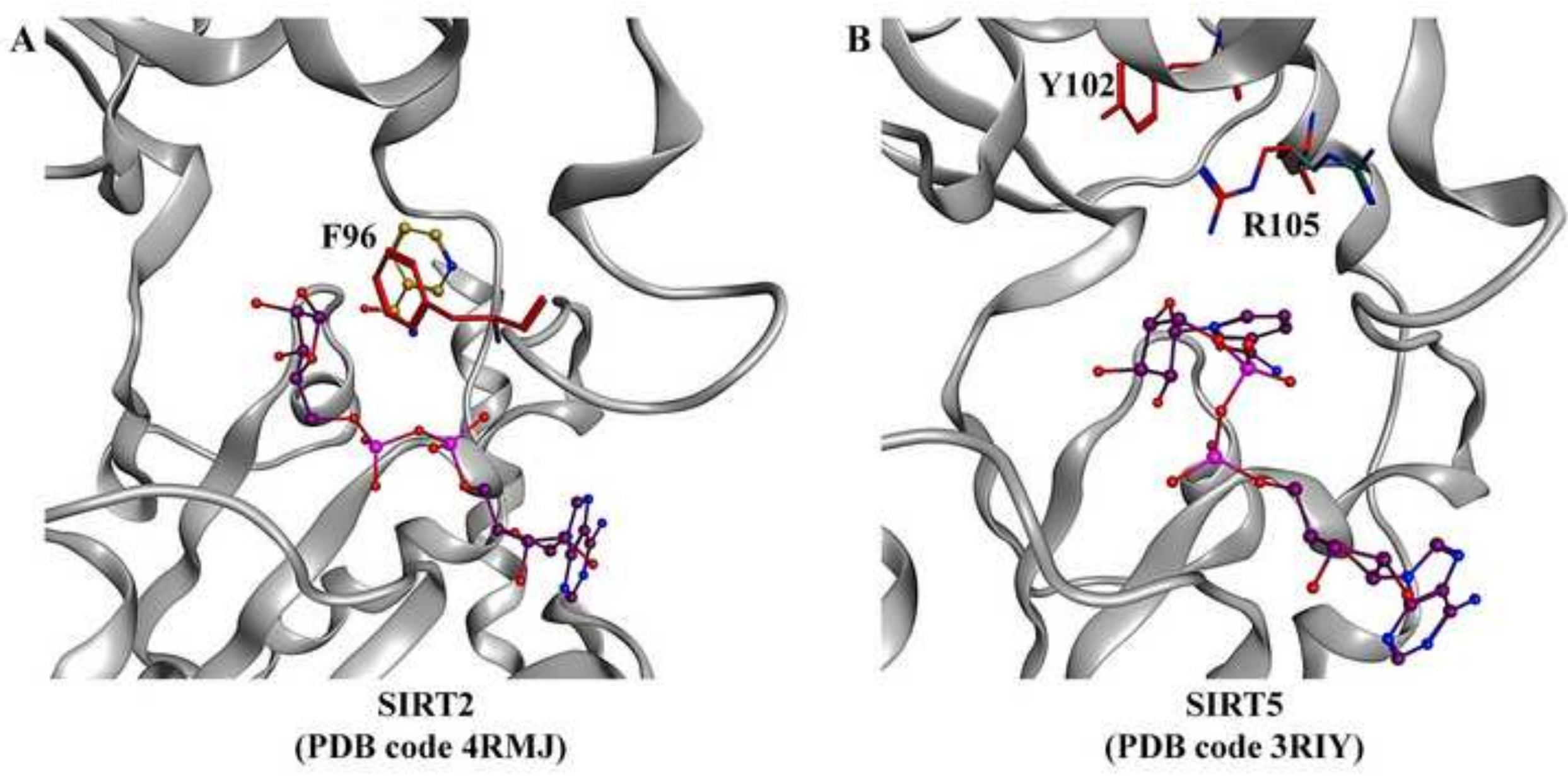